thinned out into the fibrous capsule which surrounded the clamp. No hemorrhage was encountered and the wound was closed in the ordinary manner. An examination of the clamp after its removal showed that the two blades were very nearly approximated. though between them was a thin layer of tissue. This layer proved to be a very much thimned-out and apparently clean-cut seguent of the artery. its lenoth corresponding to the width of the blades of the clamp. The walls of the vessel were easily separated, as shown in Figure 2 .

IBecause of the tendeney of the projecting ends of the original clamp to press on the adjacent structures of the neck. particularly the internal jugular roin and the trachea, which made it necessary to protect these structures from the clamp by suturing together the muscles underneath it, it was suggested that the clamp might be modified so that this objection would be overcome. With this in mind, I devised al climp consisting of a steel spring to lie parallel to the artery, wit? two 28-gauge German silver blades to fit over the artery. TTh principle of application is the same as that in the Neff elamp. that is. the grooves in the end of the blades are to be wound witls plain No. 2 catgut, but the compression in this clamp is secured by means of the spring instead of by rubluer bands, as in the original clamp. The exact size of the dimp and its method of application are shown in Jigure 3.

from our experience with this ease. we would conchus that the clamp automatically occluding the vessel is the ideal treatment for aneurysm and has a decided advantilge over the immediate ligation of the vescel

\section{CASE ILLUSTRATING VALLE OF ROENTGEN RAY IN DIAGNOSING OBSCURE FRACTURES}

H. M. Stewart, M.D., Johnstown, Pa.

History.-A boy, aged 11, was referred by lis family physician for a Roentgen examination with history of a fall from a swing, causing injury to elbow by direct force over the olecranon process.

Diagnosis.-Fracture of humerus at the base of the condyles as shown by Figure 1. Line of fracture somewliat longer behind than in front. Lower fragment drawn backward and upward by the action of the triceps, biceps and brachialis anticus muscles. Lower end of upper fragment projects in front of joint.

Treatment.-Fracture was thought to be reduced and put on an anterior angular splint before Figure 1 was taken. Tho ease after examination was referred to a surgeon who unde: anesthesia reduced fracture and put on a straight splint, Allis' method, and Figure 2 was taken. It was found that slipping had occurred after reduction (which probably happened after

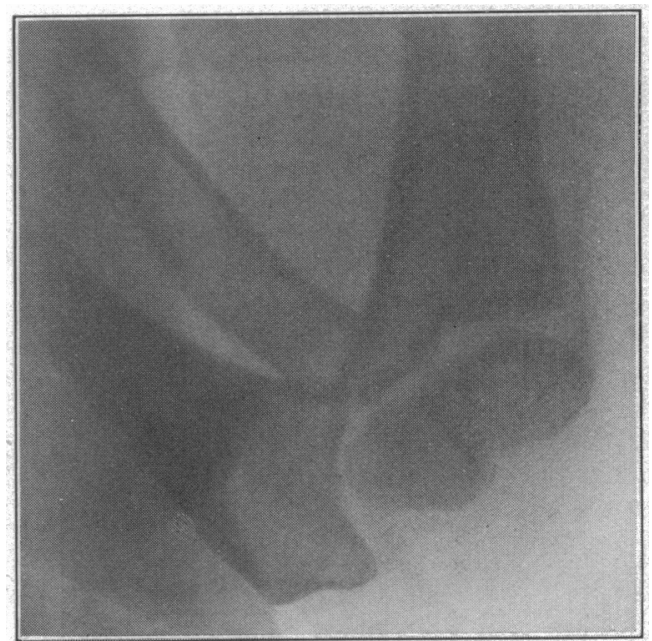

Ficr. 3-Fracture reduced and dressed in Jones position.

putting on anterior angular splint) and it was decided to change to Jones' position. Figure 3 shows fracture reduced and dressed in acute flexion. Dressing was done in this position for four weeks, when gentle passive motion was begun. Figure 4 was taken three months later. It shows fragments in good apposition and line of fracture well united, which was further proved by perfect use of the arm.

The history of the case illustrates that the general practitioner must realize the advantages of this method of diag. nosis to his patient. The surgeon who neglects its use, neglects his interests and those of his patient. The best results can be

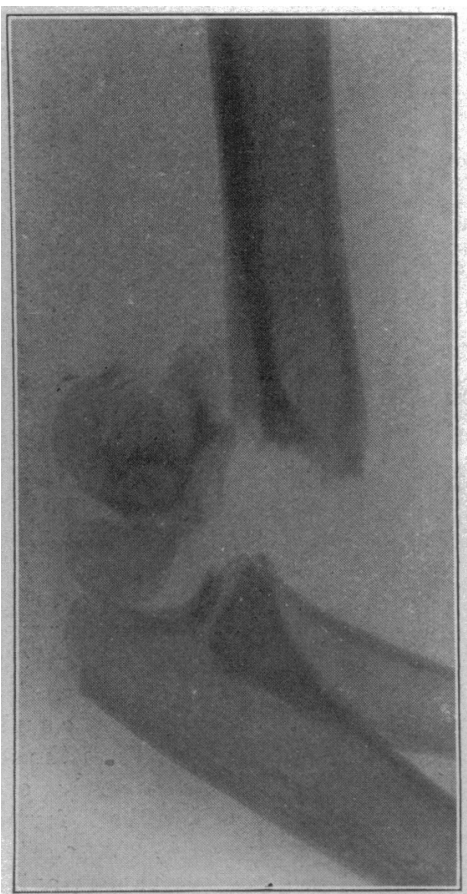

Fig. 1. Fracture of humerus above condyles thought to be reduced and dressed on anterior angular splint.

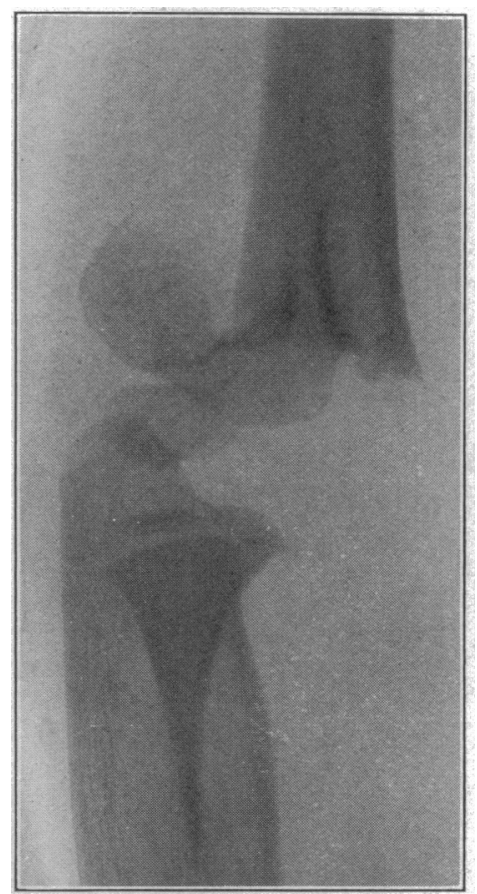

Fig. 2.-Partially reduced under anesthesia and dressed on straight splint.

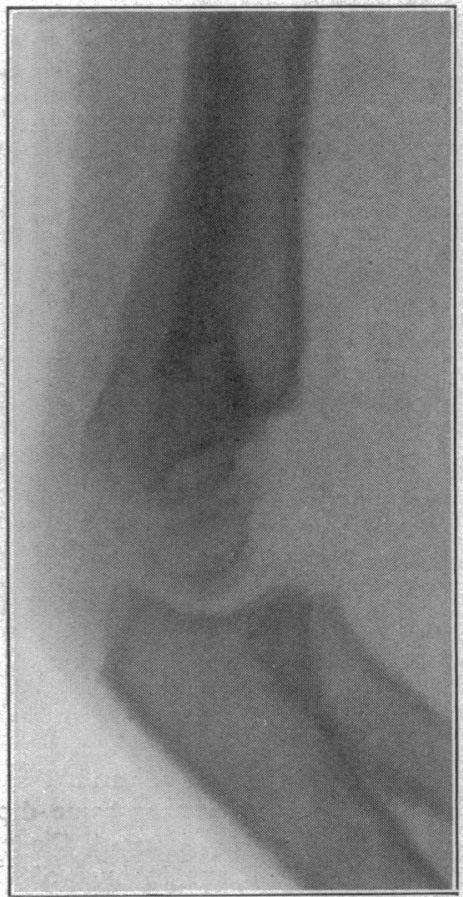

Fig. 4. - Elbow three months later; perfect use of arm. 
obtained by making the roentgenogram before any attempt at reduction has been made as the knowledge gained prevents unnecessary trauma and manipulation, thereby greatly facilitating bony union and avoiding the danger of ununited fractures.

The practitioner must insist that a roentgenogram be taken in every case. This must be made and read by an experienced operator and is the evidence which must be preserved. A picture taken for diagnosis, together with a similar picture taken after the fracture is set, is the absolute evidence that his work has been properly done.

This case illustrates the accuracy in Roentgen diagnosis. The physician in every case to safeguard his and his patients interests must insist on its employment. Thus with both protected, he can himself treat many more of his own patients and determinc readily when operative intervention is necessary.

\section{ABSCESS CAUSED BY FISH-BONE-HEMATEMESIS CONTROLLED BY HOT WATER}

W. Hersey Thomas, M.D., Philadelphia

Assistant Professor of Surgery, Medico-Chirurgical College; Assistant Surgeon to the Medico-Chirurgical and Philadelphia General Hospitals

The cases about to be reported are from the surgical service of Dr. William L. Rodman, to whom I am indebted for the privilege of operating on and reporting them. Each is characterized by features which make it worthy of record. They occurred in the summer of 1912.

CAse 1.-An abscess of the abdominal wall containing a fishbone which had ulcerated through some portion of the gastrointestinal tract, presumably the stomach.

History.-J. H., aged 45 , a victim of chronic alcoholism, was admitted Sept. 17, 1912, with a mass in the abdominal wall just below the fundus of the gall-bladder. The liver was much enlarged but seemed to have no connection with the swelling. The mass was the size of a man's fist, evidently inflammatory and red, soft and fluctuating in the center. The notes of a prior admission six weeks earlier showed that the swelling was then present although it caused the patient no distress and showed no inflammatory action. The statements of the patient were unreliable but it seemingly had caused him great annoyance for several weeks prior to September 17 .

operation.-The case having been diagnosed as one of abscess of the abdominal wall, a vertical incision 3 inches in length was made over the swelling. After the eseape of about 8 ounces of foul-smelling sanious pus, a slit-like opening 1 inch in length was discovered in the right rectus muscle, with hard, organized and almost cicatricial margins. The greater portion of the abscess cavity was beneath the rectus and a finger passed through the slit-like opening in this muscle discovered a long thin curved object ( $1 / 16$ inch by $1 \%$ inches) having the phys. ical characteristics of a fish-bone. One end of the bone seemed to be loosely imbedded in the substance of the rectus and the free end pointed upward and to the left in the direction of the stomach. The peritoneal cavity was not opened on account of the danger of spreading the infection. The abscess cavity was gently scrubbed with gauze, well irrigated with hot normal saline solution, and packed with iodoform gauze.

Postoperative History. - The case passed out of my hands ten days later with the termination of the summer service. The bedside notes show an uneventful recovery. When seen one year after the operation the ablominal wall was in good condition and had caused him no trouble.

As no scar was pr-jent over the swelling prior to the operation, as the fish-bone was found beneath the rectus and as the greater portion of the abscess cavity was deeper than this muscle, the obvious conclusion was that the foreign body had uleerated through from some portion of the gastro-intestinal tract.

I have just learned that a second fish-bone was removed from the left rectus by my colleague, Dr. W. P. Hearn, on Dec. 4, 1913. This was fifteen months after the first operaticn. The second fish-bone was surrounded by sear tissue and had recently caused the patient much discomfort.

CASE 2.-Postoperative hematemesis following gastroplication and posterior gastrojejunostomy for a dilated and ptosed stomach, the hemorrhage being controlled by the direct application of hot water (130 F.) by means of a stomach-tube.

History.-R. B., a textile worker, aged 53, single, was admitted to the men's surgical ward of the Philadelphia General Hospital, July 27, 1912, complaining of sensations of painful weight and distress in the umbilical region soon after eating. He had had stomach trouble for more than thirty years. He did not use alcohol or tobacco. He gave a history of gonorrhca six years before, but none of lues. About a year before admission, he was jaundiced and at that time his stools were clay-colored. He was thin, nervous, and suffering from marked melancholia. His stomach was dilated, ptosed, and showed marked loss of motor power. Repeated analyses of the gastric contents were made. They usually gave a neutral or slightly acid reaction, contained no blood, no hydrochloric acid, showed a trace of lactic acid and had a total acidity which varied between 15 and 2. Oppler-Boas bacilli were absent. The red blood-corpuscles were usually about 4,000,000 , the white blood-corpuscles 8,000 ; the hemoglobin percentage on admission was 80 , but fell to 60 some weeks later. The urine was reported as containing nothing abnormal.

operation. - When the abdomen was opened a markedly dilated and ptosed stomach was found, the greater curvature being two finger-breadths below the umbilicus and the lesser curvature displaced far below its normal position. As the gastrohepatic omentum was as thin as tissue-paper and the gastrophrenic $\varepsilon$ nd hepatoduodenal ligaments were not much more robust, shortening of these structures was impracticable; consequently a no-loop posterior gastrojejunostomy was performed and this procedure was followed by a plication of the anterior gastric wall from the cardia to within 2 inches of the pylorus. Six sutures of Pagenstecher linen thread were used for the gastroplication, the anterior gastric wall being thrown into folds parallel with the long axis of the stomach and the greater curvature drawn up as closely as possible to the lesser one. The length of the anastomotic opening between the stomach and jejunum was about 2 inches. During the entire operation the hemostasis was perfect and nothing occurred which could furnish a basis of explanation for the subsequent hematemesis.

Hematemesis and Treatment.-When the patient was returned to the ward at $12: 20 \mathrm{p}$. m. his temperature was $98.4 \mathrm{~F}$., pulse 120 and respiration 20 . At $1: 30 \mathrm{p}$. m. the temperature was 98 , pulse 104, respiration 20 . At $2 \mathrm{p}$. $\mathrm{m}$. he was asleep. At $3 \mathrm{p}, \mathrm{m}$. he vomited 1 ounce of blood. At $3: 30 \mathrm{p}$. m. he vomited 10 ounces of bright red blood; his pulse was still 120 . He was then given an enema of 3 pints of normal saline solution at a temperature of $120 \mathrm{~F}$. Soon after this he again vomited 10 ounces of bright red blood, the pulse rising to 128 . At $5: 15 \mathrm{p}$. $\mathrm{m}$. he vomited 5 ounees of blood, his pulse remain. ing about the same as before. The saline enema was retained. At 6:15 p. m. the patient vomited 10 ounces of blood. At $6: 35 \mathrm{p} . \mathrm{m}$. a stomach-tube was passed and the stomach washed out with small quantities of normal saline solution at a tem. perature of $130 \mathrm{~F}$. The funnel was held low, the fluid allowerl to run in at any one time being small in amount to avoid a dilatation of the viscus. The washing was kept up until 4 quarts of the normal saline solution had been employed. There was no return of the hemorrhage. At $7: 30 \mathrm{p}$. m. the patient was asleep. Pulse, 144. At 8:30 he was given hypodermoclysis ( 1 pint of normal saline with 1 dram of $1: 1,000$ solution of epinephrin). At $11: 30 \mathrm{p}$. $\mathrm{m}$. he had a hypodermic injection of atropin sulphate, $1 / 150$ grain. After midnight he slept soundly most of the time but was disturbed ocea: sionally by hiccup. During the next four days, he received enteroclysis twice daily ( 1 pint of normal saline). The subsequent recovery was uneventful and the patient was sent to the out-wards November 19 . As the result of the operation the digestion was much improved and the distress after eating disappeared. The motor power of the stomach returned and the patient's color was markedly improved. His molen- 